\title{
The prognostic value of arterial stiffness in systolic heart failure
}

\author{
Şerafettin Demir ${ }^{1}$, Onur Akpınar ${ }^{2}$, Oguz Akkus ${ }^{3}, \mathrm{Kamil} \mathrm{Nas}^{4}$, Ilker Unal ${ }^{5}$, \\ Frenc Molnar ${ }^{6}$, Ahmet Demir ${ }^{7}$, Miklós Illyés ${ }^{8}$, Esmeray Acartürk $^{3}$ \\ ${ }^{1}$ Department of Cardiology, Adana State Hospital, Adana, Turkey \\ ${ }^{2}$ Department of Cardiology, BSK Metropark Hospital, Adana, Turkey \\ ${ }^{3}$ Department of Cardiology, Çukurova University, School of Medicine, Adana, Turkey \\ ${ }^{4}$ Radiology Department, Szent Janos Hospital, Budapest, Hungary \\ ${ }^{5}$ Department of Biostatistics, Çukurova University, School of Medicine, Adana, Turkey \\ ${ }^{6}$ Budapest University Technology and Echonomics, Budapest, Hungary \\ ${ }^{7}$ Department of Plastic, Reconstructive and Aesthetic Surgery, Antalya Education \\ and Research Hospital, Antalya, Turkey \\ ${ }^{8}$ Heart Institute, Pecs University Faculty of Medicine, Pecs, Hungary
}

\begin{abstract}
Background: Increased arterial stiffness is an indicator of mortality. This study consists of an 18-month follow-up of the mortality in advanced heart failure patients with increased arterial stiffness.
\end{abstract}

Methods: The study followed up 98 patients with a diagnosis of heart failure in NYHA class III and IV (76 males, 22 females and mean age of $60 \pm 12$ years) with a left ventricular ejection fraction $\leq 35 \%$ as determined by the Simpson method. Augmentation index (Aix) and pulse wave propagation velocity $(P W V)$ parameters were used as indicators of arterial stiffness. Aix and $P W V$ values were measured by arteriography.

Results: 36 patients died. Both Aix and PWV were powerful determinants of mortality, independent of other prognostic variables ( $p=0.013$, OR: 0.805; $p=0.025$, OR: 0.853). A cutoff value for Aix of -14.33 gave 91.2\%, 80.3\% sensitivity and specificity. A cutoff value for $P W V$ of 11.06 gave $82.4 \%, 65.4 \%$ sensitivity and specificity mortality was predicted. Left ventricular ejection fraction ( $p=0.008$, OR: 0.859) and B-type natriuretic peptide ( $p=0.01,0 R: 0.833)$ was the other independent determinant of mortality. A significant difference was found in both Aix and PWV between the compensated measurements and decompensated heart failure measurements made in 70 patients $(p=0.035, p=0.048)$.

Conclusions: Measurement of arterial stiffness is a convenient, inexpensive and reliable method for predicting mortality in patients with advanced heart failure. (Cardiol J 2013; 20, 6: 665-671)

Key words: heart failure, arterial stiffness, mortality, prognosis

Address for correspondence: Şerafettin Demir, MD, Adana State Hospital, Department of Cardiology, 01270, Adana, Turkey, tel./fax: +90 53362719 91, e-mail: demirkardiyoloji@hotmail.com

Received: 06.02.2013

Accepted: 19.06.2013 


\section{Introduction}

Heart failure (HF) is the inability of the heart to create sufficient blood flow to meet the metabolic needs of the body [1]. Despite many advances in diagnosis and treatment, $\mathrm{HF}$ still affects about 20 million people worldwide [2]. A permanent increase in the vascular load as in chronic arterial hypertension is a significant cause of HF. Ventricular failure is quite sensitive to changes in pressure and vascular load, and minor increases in vascular load can lead to disproportional major reductions in the cardiac output $[3,4]$. For these reasons, vasodilator treatment of $\mathrm{HF}$ is common $[5,6]$.

Many factors have been proposed as indicators of survival in HF; however there are as yet no adequate trials to show the value of any of these variables [7]. This trial was designed to investigate the value of arterial stiffness in predicting the prognosis in patients with advanced HF.

\section{Methods}

The trial included 98 NYHA stage III-IV patients (76 males, 22 females and mean age: $59.4 \pm$ \pm 11.6 years) with a left ventricular ejection fraction (LVEF) $\leq 35 \%$ as determined by echocardiography. All patients had ischemic cardiomyopathy due to atherosclerotic heart disease. Patients with atrial fibrillation, frequent ventricular extra ectopic beats, advanced renal failure (serum creatinine $>2.0 \mathrm{mg} / \mathrm{dL}$ ), hypothyroidism, hyperthyroidism, respiratory diseases (COPD, chronic bronchitis, pulmonary embolism), primary pulmonary hypertension, acute coronary syndrome within the last 2 months, isolated right $\mathrm{HF}$, congenital cardiac diseases and advanced valvular disease (mitral stenosis, aorta stenosis and failure) were excluded from the trial. For patients included in the trial, data on risk factors such as age, gender, hypertension, diabetes, hyperlipidemia, coronary artery disease, smoking, familial history of cardiac diseases and drugs received were recorded. The patients were questioned for complaints of dyspnea, chest pain and palpitations and underwent relevant additional investigations. Decompensated $\mathrm{HF}$ and hospitalization were regarded as morbidity. Arterial stiffness measurements were repeated during hospitalization. General examination was directed to indicate functional incapacity including skin paleness, coldness of the limbs, peripheral cyanosis and cardiac cachexia. Jugular venous distention, hepatomegaly, hepatojugular reflux, ascites and pretibial edema were recorded as the findings of stasis. Cardiac murmurs and third and fourth cardiac sounds were considered to represent cardiac pathology. Pulse examination of the upper and lower limbs was performed. Additional investigations were performed in patients with tachycardia. Body mass index (BMI) was calculated. Waist circumference over the umbilical line and hip circumference including the outmost point of the hip were measured. Blood pressure was measured by mercury sphygmomanometer. Pulse rate was measured over 1-min.

The patients also underwent 12-lead ECG; pathological Q waves, branch blocks, atrial fibrillation, ventricular arrhythmias, ST segment and $\mathrm{T}$ wave changes were noted. Telecardiography was performed to investigate cardiac size, pulmonary parenchymal tissue, pulmonary vascular structures, abnormal densities and pleural fluid. In addition, whole blood count, fasting blood glucose, blood urea nitrogen, creatinine, serum sodium, potassium levels, HDL-cholesterol, LDL-cholesterol, total cholesterol, triglyceride levels, albumin, total protein, liver, B-type natriuretic peptide (BNP), $\mathrm{C}$-reactive protein and thyroid function test measurements were performed.

The local ethical committee approved this study. Informed consent was obtained from all patients.

\section{Echocardiography}

A detailed echocardiographic examination was performed by an experienced technician without reference to the clinical findings, using an Acuson Sequoia C 256 (General Electric), USA) cardiovascular imaging system providing 2-dimensional (2D) echocardiography, spectral Doppler and color Doppler flow mapping information using a 2.5 or $3.5 \mathrm{MHz}$ duplex transducer and a $1.9 \mathrm{MHz}$ sound only continuous wave Doppler transducer. Standard views were obtained with the patient in the left lateral position. Images were stored on videotape. M-mode, 2D, color flow, and Doppler studies were performed on all patients. LV function was assessed qualitatively as normal, or as mild, moderate or severe dysfunction. Where possible, we calculated the EF by the biplane disc summation method (Simpson's rule) [8].

\section{Arterial stiffness measurement}

Arterial stiffness was assessed noninvasively with the arteriograph (TensioMed, Budapest, Hungary) [9]. Oscillometric pulse waves from the participants. We measured the distance between the jugulum-symphysis (which is the same as by the invasive method, the distance between the aor- 
tic root and the aortic bifurcation), and pulse wave propagation velocity (PWV) was calculated. Pulse waves were recorded at supra-systolic pressure. The oscillation signs were identified from the cuff inflated at least $>35 \mathrm{~mm} \mathrm{Hg}$ above the systolic blood pressure. In this state brachial artery occlusion was complete; it functions as a membrane before the cuff. Pulse waves hit the membrane and are measured as oscillometric wave, shown on the monitor. The augmentation index (Aix) was defined as the ratio of the difference between the second (P2 - appearing because of the reflection of the first pulse wave) and first systolic peaks (P1 - induced by the heart systole) to pulse pressure (PP), and was expressed as a percentage of the ratio $(\mathrm{AI}=[\mathrm{P} 2-\mathrm{P} 1] / \mathrm{PP} \times 100)$.

During measurements special attention was paid to the following: the avoidance of speaking muscle movement, especially the arms. Muscle movement distorts the shape of the measured pulse wave. The patient should not have taken nitrates or eaten a large meal, and should avoid black coffee, smoking up to $3 \mathrm{~h}$ previously and alcohol for $10 \mathrm{~h}$ before the examination. Sleeping is not allowed! Physical and mental relaxation is necessary for at least $10 \mathrm{~min}$ before measurement. Distractions should be avoided during measurement, and complete silence is ideal. If the 'white coat effect' is suspected, several measurements should be made.

\section{Statistical analysis}

All analyses were performed using SPSS statistical software package version 16.1. Continuous variables in the group data are indicated as mean \pm standard deviation (SD). Categorical variables are given in numbers and percentages. An independent sample t-test and multivariate analysis (ANOVA) were performed according to the range of continuous variables between the groups. For nonparametric tests, Mann-Whitney U and Kruskal-Wallis tests were applied. A $\chi^{2}$ test was used to compare categorical variables. Parametric or nonparametric (Pearson and Spearman) correlation analysis was performed to identify the relationship between continuous variables. Multivariate binary logistic regression analysis was performed to identify factors affecting mortality. A per unit increase in the variables identified from the study increase or decrease the risk by a factor specified by the odds ratio. ROC analysis was used to determine the cutoff value for the variables as predictors in mortality. Statistical significance was accepted as $\mathrm{p}<0.05$.

\section{Results}

There were 76 males and 22 females, mean age $59 \pm 11$ years; 50 patients had hypertension and 40 diabetes mellitus; 36 of the patients had died. At the 18-month follow-up point all patients or a close family member could be contacted. There was sudden cardiac death in 24 and decompensation following hospitalization in 12 . During the follow-up, all 70 patients were hospitalized with the diagnosis of decompensated cardiac failure and followed up. There were no significant differences between deceased patients and survivors, or hospitalized and non-hospitalized, with respect to taking beta-blockers, furosemide, digoxin, spironolactone, statin, or angiotensin receptor blocker and angiotensin converting enzyme inhibitor use. The demographic characteristics an laboratory findings of patients were determined in Table 1.

LV end-systolic and end-diastolic size and volume were significantly greater and LVEF was significantly lower in those who died and those hospitalized (Table 2).

The values of Aix vs. PWV differed significantly between the patients who died and the survivors, and between the hospitalized and non-hospitalized patients. During decompensation, Aix and PWV were greater than when the same patients were adequately treated (Table 3 ).

Deceased patients had a correlation between arterial stiffness parameters and BNP, EF, estimated glomerular filtration rate (e-GFR), and LV end-diastolic volume. In hospitalized patients there was a correlation between arterial stiffness parameters and BNP, ejection fraction, and LV end-diastolic volume (Table 4).

An independent association between mortality and LVEF, BNP, PWV and Aix is shown below the logistic regression analysis in Table 5.

The area under the ROC curve of the relationship between HF patients' Aix and mortality was $90.7 \%$ (Fig. 1). The Aix for all patients was found to be a predictor of mortality, with the cutoff value at -13.35 , with $91.8 \%$ sensitivity and $81.9 \%$ specificity.

The area under the ROC curve of the relationship between mortality in HF patients and PWV was $81.7 \%$. In this analysis the cutoff value for PWV as a predictor of mortality was taken as 10.8 with $83.3 \%$ sensitivity and $66.4 \%$ specificity.

The area under the curve of the logistic regression analysis shows Aix to be a stronger independent determinant of mortality than PWV (Fig. 1). 
Table 1. Demographic characteristics and laboratory findings of patients.

\begin{tabular}{lcccccc}
\hline Characteristics & $\begin{array}{c}\text { Deceased } \\
(\mathbf{n}=\mathbf{3 6})\end{array}$ & $\begin{array}{c}\text { Survivors } \\
(\mathbf{n}=\mathbf{6 2})\end{array}$ & $\mathbf{P}$ & $\begin{array}{c}\text { Hospitalized } \\
(\mathbf{n}=\mathbf{7 0})\end{array}$ & $\begin{array}{c}\text { Non-hospita- } \\
\text { lized } \mathbf{( n = 2 8 )}\end{array}$ & $\mathbf{P}$ \\
\hline Age [years] & $60.5 \pm 11.2$ & $59.5 \pm 11.3$ & 0.174 & $59.8 \pm 10.7$ & $60.5 \pm 10.9$ & 0.233 \\
Sex (female/male) & $8 \% / 28 \%$ & $14 \% / 48 \%$ & 0.201 & $15 \% / 70 \%$ & $7 \% / 28 \%$ & 0.197 \\
Duration of disease & $5.4 \pm 4.5$ & $4.6 \pm 3.1$ & 0.007 & $5.2 \pm 4.4$ & $3.9 \pm 2.8$ & 0.022 \\
[years] & & & & & & \\
Hypertension & $23(63.8 \%)$ & $27(43.5 \%)$ & 0.052 & $36(51.4 \%)$ & $14(50.0 \%)$ & 0.612 \\
Diabetes & $15(41.6 \%)$ & $25(40.3 \%)$ & 0.116 & $28(40.0 \%)$ & $12(42.8 \%)$ & 0.153 \\
Smoker & $26(58.8 \%)$ & $25(47.1 \%)$ & 0.145 & $34(48.6 \%)$ & $25(57.4 \%)$ & 0.235 \\
BMI [kg/m $\left.{ }^{2}\right]$ & $26.4 \pm 3.8$ & $26.2 \pm 4.1$ & 0.085 & $26.1 \pm 3.9$ & $26.4 \pm 3.8$ & 0.108 \\
SBP [mm Hg] & $125 \pm 20$ & $146 \pm 26$ & $<0.001$ & $128 \pm 22$ & $143 \pm 21$ & $<0.001$ \\
DBP [mm Hg] & $75.7 \pm 8.8$ & $87.4 \pm 16.1$ & $<0.001$ & $77.9 \pm 9.1$ & $85.4 \pm 14.6$ & $<0.001$ \\
Mean BP [mm Hg] & $107 \pm 18.9$ & $92.2 \pm 11.3$ & $<0.001$ & $106 \pm 17.9$ & $91.4 \pm 10.8$ & $<0.001$ \\
Pulse pressure [mm Hg] & $50.7 \pm 15.4$ & $40.9 \pm 6.5$ & $<0.001$ & $52.6 \pm 14.6$ & $43.9 \pm 6.7$ & $<0.001$ \\
Pulse [bpm] & $86.8 \pm 13.4$ & $75.0 \pm 14.6$ & $<0.001$ & $85.2 \pm 12.5$ & $74.0 \pm 13.9$ & $<0.001$ \\
Leukocyte $[\mu \mathrm{L}]$ & $8.1 \pm 2.7$ & $8.3 \pm 2.5$ & 0.670 & $8.5 \pm 2.9$ & $8.0 \pm 2.4$ & 0.324 \\
Hemoglobin [g/dL] & $12.2 \pm 2.5$ & $12.9 \pm 3.0$ & 0.686 & $11.5 \pm 3.1$ & $12.9 \pm 3.1$ & 0.233 \\
Hematocrit [\%] & $36.3 \pm 6.1$ & $39.1 \pm 5.6$ & 0.774 & $34.1 \pm 4.6$ & $36.4 \pm 6.5$ & 0.512 \\
Glucose [mg/dL] & $148 \pm 105$ & $138 \pm 70$ & 0.135 & $142 \pm 73$ & $144 \pm 115$ & 0.188 \\
BUN [mg/dL] & $31.3 \pm 10.2$ & $23.6 \pm 12.4$ & 0.004 & $30.3 \pm 9.9$ & $27.1 \pm 12.6$ & 0.011 \\
Creatinine [mg/dL] & $1.3 \pm 1.8$ & $1.4 \pm 0.4$ & 0.003 & $1.3 \pm 1.7$ & $1.3 \pm 1.2$ & 0.006 \\
Sodium [mmol/L] & $135.3 \pm 4.5$ & $139 \pm 4.0$ & $<0.001$ & $135.1 \pm 4.7$ & $139.3 \pm 4.5$ & $<0.001$ \\
Potassium [mmol/L] & $4.6 \pm 0.8$ & $4.5 \pm 0.5$ & 0.533 & $4.6 \pm 0.5$ & $4.6 \pm 0.9$ & 0.463 \\
Total protein [mg/dL] & $7.6 \pm 0.6$ & $7.8 \pm 0.9$ & 0.330 & $7.5 \pm 0.9$ & $7.7 \pm 1.0$ & 0.228 \\
BNP [pg/mL] & $6215 \pm 3745$ & $2562 \pm 2723$ & $<0.001$ & $5473 \pm 4013$ & $4167 \pm 3750$ & $<0.001$ \\
e-GFR & $47.2 \pm 9.5$ & $56.3 \pm 14.8$ & $<0.001$ & $48.8 \pm 13.4$ & $53.2 \pm 10.6$ & $<0.001$ \\
\hline
\end{tabular}

$\mathrm{BMI}$ - body mass index; BP — blood pressure; BUN — blood urea nitrogen; BNP — B type natriuretic peptide; e-GFR — estimated glomerular filtration rate; DBP — diastolic blood pressure; SBP — systolic blood pressure

Table 2. Echocardiographic findings of deceased and surviving patients.

\begin{tabular}{|c|c|c|c|c|c|c|}
\hline Echocardiographic findings & $\begin{array}{c}\text { Deceased } \\
(n=36)\end{array}$ & $\begin{array}{l}\text { Survivor } \\
(\mathrm{n}=62)\end{array}$ & $\mathbf{P}$ & $\begin{array}{l}\text { Hospitalized } \\
\quad(n=70)\end{array}$ & $\begin{array}{l}\text { Non-hospita- } \\
\text { lized }(n=28)\end{array}$ & $\mathbf{P}$ \\
\hline LV end-diastolic size [mm] & $65.6 \pm 6.6$ & $59.6 \pm 3.6$ & $<0.001$ & $64.1 \pm 6.3$ & $60.6 \pm 3.2$ & 0.003 \\
\hline LV end-systolic size [mm] & $57.8 \pm 5.2$ & $49.7 \pm 3.9$ & $<0.001$ & $56.8 \pm 6.1$ & $51.7 \pm 4.4$ & 0.012 \\
\hline LV end-diastolic volume [mL] & $245.6 \pm 30.5$ & $199.6 \pm 26.7$ & $<0.001$ & $245.6 \pm 30.5$ & $199.6 \pm 26.7$ & $<0.001$ \\
\hline LV end-systolic volume [mL] & $203.1 \pm 27.1$ & $161.9 \pm 26.7$ & $<0.001$ & $198.4 \pm 31.1$ & $168.9 \pm 31.5$ & $<0.001$ \\
\hline LV ejection fraction [\%] & $24.7 \pm 2.8$ & $28.9 \pm 1.9$ & $<0.001$ & $25.2 \pm 2.5$ & $28.8 \pm 2.2$ & 0.001 \\
\hline
\end{tabular}

LV - left ventricular

\section{Discussion}

The main finding of our study is that arterial stiffness is a strong predictor of mortality in advanced HF, independently of other prognostic variables. Previous studies have focused on multiple variables to predict the prognosis of $\mathrm{HF}$. Decreased systolic and diastolic blood pressure [8], increased resting pulse rate $[9,10]$ and PP [8] are all important in the prognosis of HF patients; they emerged as important in our study too.
Natriuretic peptide levels are useful biochemical markers in diagnosis, risk evaluation and follow up in heart diseases $[11,12]$. There is a positive relationship between plasma natriuretic peptide levels and PWV [13, 14]. Kaji et al. [15] reported the existence of an association between plasma BNP and the radial Aix. Sakaguri et al. [16] showed a significant relation between BNP and aortic stiffness in patients with coronary artery disease. In our study BNP concentrations were greater in the hospitalized and deceased groups and there was 
Table 3. Comparison of the pulse wave velocity (PWV) and the augmentation index (Aix) values between the deceased vs. surviving patients, hospitalized vs. non-hospitalized patients and compensation vs. decompensation.

\begin{tabular}{lcc}
\hline & Aix [\%] & PWV [m/s] \\
\hline $\begin{array}{l}\text { Deceased } \\
(\mathrm{n}=36)\end{array}$ & $4.2 \pm 17.8$ & $13.8 \pm 2.9$ \\
$\begin{array}{l}\text { Survivor } \\
(\mathrm{n}=62)\end{array}$ & $-31.3 \pm 18.8$ & $10.2 \pm 2.2$ \\
$\mathrm{P}$ & $<0.001$ & $<0.001$ \\
$\begin{array}{l}\text { Hospitalized } \\
(\mathrm{n}=70)\end{array}$ & $-15.2 \pm 26.7$ & $11.9 \pm 3.2$ \\
$\begin{array}{l}\text { Non-hospitalized } \\
(\mathrm{n}=28)\end{array}$ & $-25.3 \pm 17.4$ & $10.8 \pm 2.5$ \\
$\mathrm{P}$ & 0.035 & 0.048 \\
$\begin{array}{l}\text { Decompensation } \\
(\mathrm{n}=70)\end{array}$ & $1.8 \pm 18.4$ & $11.9 \pm 3.2$ \\
$\begin{array}{l}\text { Compensation } \\
(\mathrm{n}=70)\end{array}$ & $-15.2 .2 \pm 26.7$ & $9.8 \pm 3.1$ \\
$\mathrm{P}$ & $<0.001$ & $<0.001$ \\
\hline
\end{tabular}

a significant correlation between arterial stiffness indicators. In multivariate analysis of laboratory values, BNP levels were an independent prognostic determinant of mortality.

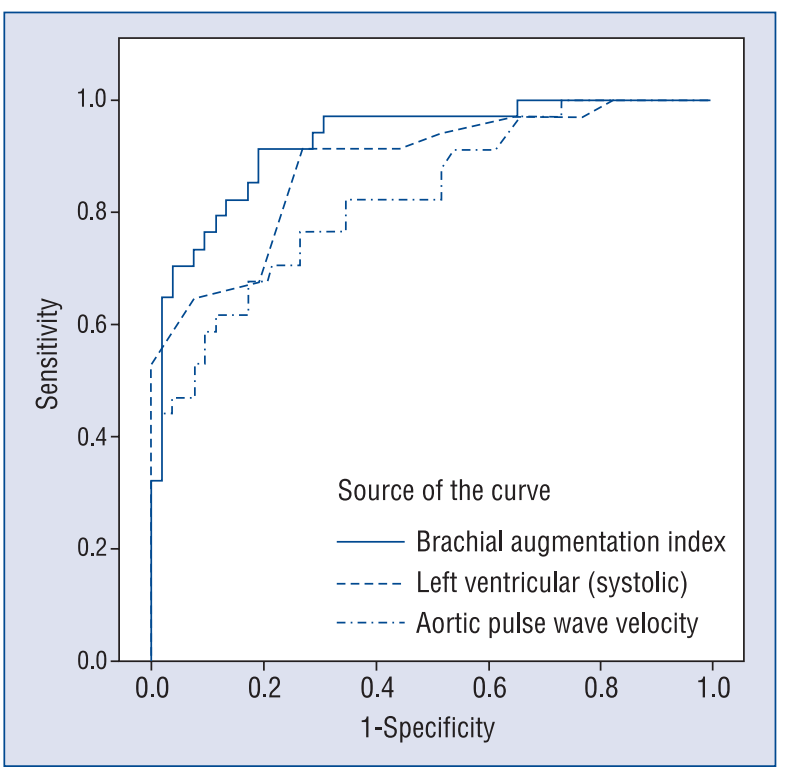

Figure 1. ROC curve.

Renal insufficiency, common in patients with HF, worsens the prognosis [17-20]. The present results agree with the hypothesis that mild impairment of renal function might increase arterial stiffness. Schillaci et al. [21] found that decreased

Table 4. Correlation analysis of augmentation index and pulse wave velocity.

\begin{tabular}{lcccccc}
\hline & Deceased & $\begin{array}{c}\text { Aix brachial } \\
{[\%]}\end{array}$ & $\begin{array}{c}\text { PWV } \\
{[\mathrm{m} / \mathrm{s}]}\end{array}$ & Hospitalized & $\begin{array}{c}\text { Aix brachial } \\
{[\%]}\end{array}$ & $\begin{array}{c}\text { PWV } \\
{[\mathrm{m} / \mathrm{s}]}\end{array}$ \\
\hline BNP [pg/mL] & $\mathrm{r}$ & 0.479 & 0.343 & $\mathrm{r}$ & 0.384 & 0.312 \\
& $\mathrm{p}$ & 0.000 & 0.001 & $\mathrm{p}$ & 0.000 & 0.004 \\
e-GFR & $\mathrm{r}$ & 0.398 & 0.321 & $\mathrm{r}$ & -0.197 & -0.182 \\
& $\mathrm{p}$ & 0.001 & 0.003 & $\mathrm{p}$ & 0.068 & 0.092 \\
LVEF [\%] & $\mathrm{r}$ & -0.471 & -0.442 & $\mathrm{r}$ & -0.284 & -0.235 \\
& $\mathrm{p}$ & 0.000 & 0.000 & $\mathrm{p}$ & 0.012 & 0.028 \\
LVEDV [mL] & $\mathrm{r}$ & 0.422 & 0.389 & $\mathrm{r}$ & 0.278 & 0.222 \\
& $\mathrm{p}$ & 0.000 & 0.001 & $\mathrm{p}$ & 0.009 & 0.039 \\
\hline
\end{tabular}

Aix - augmentation index; BNP - B-type natriuretic peptide; e-GFR - estimated glomerular filtration rate; LVEDD — left ventricular end-diastolic volume; LVEF — left ventricular ejection fraction; PWV — pulse wave velocity

Table 5. Independent determinants of mortality in patients with heart failure; age adjusted odds ratio were given.

\begin{tabular}{lccc}
\hline & Odds ratio & 95\% confidence interval & P \\
\hline Augmentation index $[\%]$ & 1.128 & $1.026-1.240$ & 0.013 \\
Pulse wave velocity $[\mathrm{m} / \mathrm{s}]$ & 1.244 & $1.042-1.385$ & 0.025 \\
Left ventricular ejection fraction $[\%]$ & 0.859 & $0.775-0.951$ & 0.008 \\
B-type natriuretic peptide $[\mathrm{pg} / \mathrm{mL}]$ & 1.152 & $1.051-1.262$ & 0.01 \\
\hline
\end{tabular}


e-GFR was a major determinant of accelerated progression of central and peripheral arterial stiffness in hypertensive patients with normal renal function. Kwamato et al. [22] showed that decreased e-GFR is associated with an increased risk of increased PWV in the general population. Decreased GFR, and increased blood urea nitrogen and creatinine levels are significant prognostic factors for HF. In our study, e-GFR was lower in hospitalized patients and non-survivors; in the latter it was correlated to arterial stiffness. In multivariate analysis, e-GFR appeared as an independent prognostic determinant of mortality.

$\mathrm{LV}$ systolic and diastolic dysfunction in $\mathrm{HF}$ impact on mortality. LVEF is an objective and independent variable in the prognosis of HF [23]. An association between LV diastolic and systolic end size and volumes, LV mass index, left atrium diastolic size and volumes and mortality has been shown, though these indicators did not act independently [24-26]. We found an association between mortality and several echocardiographic variables; however, an independent association with mortality was found only with LVEF. There was a correlation between echocardiographic LVEF and LV end-diastolic volume and markers of arterial stiffness.

Many previous trials have assessed the prognostic importance of PWV in hypertension, diabetes, end-stage renal failure and in the elderly. In an epidemiological trial by Willum-Hansen et al. [27], the associations of PWV increase with the cardiovascular disease risk and increased mortality was demonstrated. In the Framingham cardiac trial, individuals with a high PWV value had a greater risk of cardiovascular disease mortality [7]. Our study is the first in which arterial stiffness was evaluated at the start of the trial in patients with systolic HF; arterial load is an important factor in the development of HF [3]. There is increased arterial stiffness and a decreased aortic flexibility in HF [28-32]. Arnold et al. [32] reported increased PWV in patients with moderate/ /advanced HF. Increased brachial and aortic stiffness increase the amplitude of the reflected pressure wave in patients with HF [29]. An increase in arterial stiffness is significant for mortality and the finding of recurrent myocardial infarction in patients with LV dysfunction after infarction [33]. By causing an increase in PWV, stiff conduit vessels cause the reflected wave to return in late systole rather than in diastole, impeding the forward systolic wave motion. An additional load is thus imposed on the LV, which can lead to decompensation and arrhythmias. Aix and PWV were strong predictors of mortality in non-survivors. They were also independent of other prognostic variables. Non-survivors had significantly greater arterial stiffness than those who survived.

Increased arterial stiffness is associated with decompensation [34, 35]. In patients with a low EF, the renin-angiotensin-aldosterone system and inflammatory mediators increase in activity, resulting in increased water and salt retention. This in turn leads to a further increase in arterial stiffness [34-37]. Renal function deteriorates, the response to diuretics is decreased, ventricular workload is increased, and the decompensation process accelerates [35, 37]. Our study showed that PWV and Aix were significantly lower when treatment was adequate; arterial stiffness was always greater in hospitalized patients.

\section{Conclusions}

We found measurement of arterial stiffness to be a convenient, inexpensive and reliable method for predicting mortality in patients with advanced HF. In addition, it could also be used in outpatients with $\mathrm{HF}$ to optimize treatment and thus avoid hospitalization.

\section{Limitations of the study}

Ninety-eight patients were included in our study. Therefore, studies with larger sample sizes are needed. The occurrence of ventricular and supraventricular arrhythmias adversely affect cardiac output in patients with HF, and we could not evaluate the patients with arrhythmias by arteriograph.

\section{Conflict of interest: none declared}

\section{References}

1. Hunt SA; American College of Cardiology; American Heart Association Task Force on Practice Guidelines (Writing Committee to Update the 2001 Guidelines for the Evaluation and Management of Heart Failure).ACC/AHA 2005 guideline update for the diagnosis and management of chronic heart failure in the adult: a report of the American College of Cardiology/American Heart Association Task Force on Practice Guidelines (Writing Committee to Update the 2001 Guidelines for the Evaluation and Management of Heart Failure). J Am Coll Cardiol, 2005; 46: 1-82.

2. Aaronson KD, Schwattz JS, Chen TM, Wong KL, Goin JE, Mancini DM. Development and prospective validation of a clinical index to predict survival in ambulatory patients referred for cardiac transplant evaluation. Circulation, 1997; 95: 2660-2667.

3. Cohn JN, Tam SW, Anand IS, Taylor AL, Sabolinski ML, Worcel M; A-HeFT Investigators. Effect of vasodilator therapy on mortality in chronic congestive heart failure. Results of a Veterans Administration Cooperative Study. N Engl J Med, 1986; 314: 1547-1552.

4. Abhayaratna WP, Barnes ME, O'Rourke MF, Gersh BJ, Seward JB, Miyasaka Y. Relation of arterial stiffness to left ventricular diastolic function and cardiovascular risk prediction in patients $\geq 65$ years of age. Am J Cardiol, 2006; 98: 1387-1392. 
5. Kawaguchi M, Hay I, Fetics B, Kass DA. Combined ventricular systolic and arterial stiffening in patients with heart failure and preserved ejection fraction: Implications for systolic and diastolic reserve limitations. Circulation, 2003; 107: 714-720.

6. O’Rourke MF, Staessen JA, Vlachopoulos C, Duprez D, Plante GE. Clinical applications of arterial stiffness; definitions and reference values, Am J Hypertens, 2002;15: 426-444.

7. Mitchell GF, Parise H, Benjamin EJ et al. Changes in arterial stiffness and wave reflection with advancing age in healthy men and women. The Framingham Heart Study. Hypertension, 2004; 43: 1239-1245.

8. Aronson D, Burger AJ. Relation between pulse pressure and survival in patients with decompensated heart failure. Am J Cardiol, 2004; 15: 785-788.

9. Horváth IG, Németh A, Lenkey $Z$ et al. Invasive validation of a new oscillometric device (Arteriograph) for measuring augmentation index, central blood pressure and aortic pulse wave velocity. J Hypertens, 2010; 28: 2068-2075.

10. Lechat P, Hulot JS, Escolano S et al.; on behalf of the CIBIS II Investigators . Heart rate and cardiac rhythm relationships with bisoprolol benefit and chronic heart failure in CIBIS II trial. Circulation, 2001; 103: 1428-1433.

11. Eichhorn EJ. Prognosis determination in heart failure. Am J Med, 2001; 110 (Suppl. 7A): 14S-36S.

12. Maeda K, Tsutamoto T, Wada A et al. High levels of plasma brain natriuretic peptide and interleukin- 6 after optimized treatment for heart failure are independent risk factors for morbidity and mortality in patients with congestive heart failure. J Am Coll Cardiol, 2000; 36: 1587-1593.

13. Yambe M, Tomiyama H, Koji Y et al. B-type natriuretic peptide and arterial stiffness in healthy Japanese men. Am J Hypertens, 2006; 19: 443-447.

14. Rutten JHW, Mattace-Raso FUS, Verwoert GC et al. Arterial stiffness as a determinant of increased amino terminal pro-B-type natriuretic peptide levels in individuals with and without cardiovascular disease: Rotterdam Study. J Hypertens, 2010; 28: 2061-2067.

15. Kaji Y, Miyoshi T, Doi M et al. Augmentation index is associated with B-type natriuretic peptide in central hemodynamics and NT-proBNP 1933 patients with paroxysmal atrial fibrillation. Hypertens Res, 2009; 32: 611-616.

16. Sakuragi S, Okawa K, Iwasaki J, Tokunaga N, Kakishita M, Ohe T. Aortic stiffness is an independent determinant of B-type natriuretic peptide in patients with coronary artery disease. Cardiology, 2007; 107: 140-146.

17. De Santo NG, Cirillo M, Perna A et al. The kidney in heart failure. Semin Nephrol, 2005; 25: 404-407.

18. McClellan WM, Flanders WD, Langston RD, Jurkovitz C, Presley R. Anemia and renal insufficiency are independent risk factors for death among patients with congestive heart failure admitted to community hospitals: A population-based study. J Am Soc Nephrol, 2002; 13: 1928-1936.

19. De Silva R, Nikitin NP, Witte KK et al. Incidence of renal dysfunction over 6 months in patients with chronic heart failure due to left ventricular systolic dysfunction: contributing factors and relationship to prognosis. Eur Heart J, 2006; 27: 569-581.

20. McAlister FA, Ezekowitz J, Tonelli M, Armstrong PW. Renal insufficiency and heart failure. Prognostic and therapeutic impli- cations from a prospective cohort study. Circulation, 2004; 109: 1004-1009.

21. Schillaci G, Pirro M, Mannarino MR et al. Relation between renal function within the normal range and central and peripheral arterial stiffness in hypertension. Hypertension, 2006; 48: 616-621.

23. Kawamoto R, Kohara K, Tabara Y, Miki T, Ohtsuka N, Kusunoki T, Yorimitsu N. An association between body mass index and estimated glomerular filtration rate. Hypertens Res, 2008; 31; 1559-1564.

23. Grzybowski J, Bilinska ZT, Ruzyllo W et al. Determinants of prognosis in nonischemic dilated cardiomyopathy. J Card Fail, 1996; 2: 77-85.

24. Echeverria HH, Bilsker HS, Myerburg RJ, Kessler KM. Congestive heart failure echocardiographic insights. Am J Med, 1983; 75: 750-755.

25. Dougherty AH, Naccarelli GV, Gray El, Hicks CH, Goldstein RA. Congestive heart failure with normal systolic function. Am J Cardiol, 1984; 54: 778-782.

26. Soufer R, Wohlgelernter D, Vita NA et al. Intact systolic left ventricular function in clinical congestive heart failure. Am J Cardiol, 1985; 55: 1032-1036.

27. Willum-Hansen T, Staessen JA, Torp-Pedersen C et al. Prognostic value of aortic pulse wave velocity as index of arterial stiffness in the general population. Circulation, 2006; 113: 664-670.

28. Wilkinson IB, MacCallum H, Flint L, Cockcroft JR, Newby DE, Webb DJ. The influence of heart rate on augmentation index and central arterial pressure in humans. J Physiology, 2000; 525: 263-270.

29. Nichols WW, O'Rourke MF. Cardiac failure: Clinical implications. McDonald's blood flow in arteries. $5^{\text {th }}$ Ed. Hodder Arnold; London 2005: 299-306.

30. Safar ME, O'Rourke MF. Arterial stiffness in hypertension. Vol. 23. Elsevier, Amsterdam 2006.

31. Cecelja M, Jiang B, Bevan L, Frost ML, Spector TD, Chowienczyk PJ. Arterial stiffening relates to arterial calcification but not to noncalcified atheroma in women a twin study. J Am Coll Cardiol, 2011; 57: 1480-1486.

32. Arnold JM, Marchiori GE, Imrie JR, Burton GL, Pflugfelder PW, Kostuk WJ. Large artery function in patients with chronic heart failure. Studies of brachial artery diameter and hemodynamics. Circulation, 1991; 84: 2418-2425.

33. Mitchell GF, Moye LA, Braunwald E et al.; for the SAVE Investigators. Sphygmomanometric determined pulse pressure is a powerful independent predictor of recurrent events after myocardial infarction in patients with impaired left ventricular function. Circulation, 1997; 96: 4254-4260.

34. Pepine CJ, Nichols WW, Conti CR. Aortic input impedance in heart failure. Circulation, 1978; 58: 460-465.

35. Curtis SL, Zambanini A, Mayet J et al. Reduced systolic wave generation and increased peripheral wave reflection in chronic heart failure. Am J Physiol Heart Circ Physiol, 2007; 293: 557-562.

36. Lage SG, Kopel L, Monachini MC et al. Carotid arterial compliance in patients with congestive heart failure secondary to idiopathic dilated cardiomyopathy. Am J Cardiol, 1994; 74: 691-695.

37. Wang KL, Cheng HM, Sung SH et al. Wave reflection and arterial stiffness in the prediction of 15-year all-cause and cardiovascular mortalities: A community-based study. Hypertension, 2010; 55: 799-805. 